
\title{
BResarch Soute \\ The Liquidity Spillover Effects Between the Stock Index Futures and Spot Under the Fractal Market Hypothesis
}

\section{Jingyang Zhang}

Chengdu University of Technology

XuWu ( $\nabla$ markwoo@aliyun.com )

Chengdu University of Technology https://orcid.org/0000-0003-2076-5206

\section{Ruzhen Yan}

Chengdu University of Technology

\section{Zhengjie Chun}

Chengdu University of Technology

\section{Research Article}

Keywords: liquidity spillover effects, fractal market, stock index futures, CSI 300 Index

Posted Date: December 2nd, 2021

DOI: https://doi.org/10.21203/rs.3.rs-933613/v1

License: (9) This work is licensed under a Creative Commons Attribution 4.0 International License. Read Full License 


\title{
The liquidity spillover effects between the stock index futures and spot under the fractal market hypothesis
}

\author{
Jingyang Zhang ${ }^{1}, \mathrm{Xu} \mathrm{Wu}^{1,}$, Ruzhen Yan $^{1}$, Zhengjie Chun ${ }^{2}$ \\ ${ }^{1}$ School of Business, Chengdu University of Technology, Chengdu, China \\ ${ }^{2}$ College of management science, Chengdu University of Technology, Chengdu, China
}

\begin{abstract}
:
In recent years, the extreme risk events occurred frequently in the financial market have not only brought huge losses to investors and inflicted heavy losses on the market, but also posed a severe challenge for the traditional effective market hypothesis. These extreme risk events are often accompanied by sudden plummeting of liquidity. Different from the efficient market hypothesis(EMT), firstly, this paper studies the nonlinear fluctuation characteristics and causes of contracts with different maturity periods in China stock index futures market under the framework of fractal market theory and using the multifractal detrended fluctuation model Secondly, under the framework of the fractal market theory, the existence of the liquidity spillover effect between the stock index futures and spot is tested, the direction, intensity, and contribution of spillover between stock index futures and spot are analyzed. Finally, there is a robustness test. The study finds that both stock index futures and stock index spot in China have obvious nonlinear fractal fluctuation characteristics, and stock index futures have higher degree of multifractal, the characteristics are related to correlated multifractal and distributed multifractal; the longer the maturity period of the stock index futures contract, the lower the multifractal degree; there are significant asymmetric liquidity spillover effects between the stock index futures and spot; the multifractal degree has an important influence on the intensity and contribution of the liquidity spillover effect, and the multifractal degree is inversely proportional to the intensity of liquidity spillover and the contribution of spot to futures fluctuations.
\end{abstract}

Keywords: liquidity spillover effects; fractal market; stock index futures; CSI 300 Index

* Corresponding author: Xu Wu, ORCID: 0000-0003-2076-5206, E-mail: markwoo@aliyun.com . 


\section{Introduction}

As the first stock index futures product in Chinese mainland, CSI 300 index futures have attracted extensive attention from investors since its listing. Stock index futures are the assets of stock index spot, the stock market price fluctuations will directly affect the price fluctuation of stock index futures. Because of the hedging, risk-averse and other functions, the stock index futures will in turn indirectly affect the stock market. Therefore, stock index futures and spot markets are highly dependent on each other.

At present, there are three different views on the impact of stock index futures on price volatility in the spot market: Firstly, stock index futures increase the degree of volatility of the spot market (Harris (1989), Brorse (1991), Kamara, et al (1992), Bae, et al (2004), Kittiakarasakun, et al (2013), Zhou, et al (2015)). By studying the S \& P 500, South Korea KOSPI200, and China CSI 300 index, the high leverage may increase the intensity of market speculation and investment risk, generate more "noise" trading signals, and an increase in the trading behavior of uninformed traders, the volatility of stock market will be further increased Secondly, stock index futures enhances market price discovery function and improves market efficiency and liquidity of the stock, these can effectively reduce the volatility of the stock market (Tu and Guo (2008), Kasman and Kasman (2008), Bessembinder and Seguin (2012), Li, et al (2012), Zong and Li (2013), Dai and Yin (2017), Cao and Zhang (2017)). Thirdly, the stock index futures have no definitive or significant influence on the stock market volatility (Edwards, et al (1988), Antoniou, et al (1998), Darrat, et al (2010), Tan and Sheng (2011), Xiong, et al (2014), Bohl, et al (2015)).

In financial markets, whether it is financial derivatives market or basic securities market, extreme abnormal events such as the flash crash in the US securities market, China's securities market of a thousand shares fell by the daily limit, Guangda Group 8.16 incident, and the Shanghai 50ETF options have skyrocketed in 5.25 are still fresh in our memory, the impact caused by them also yet to fade away. In fact, these extreme events always are accompanied by a temporary and extreme lack of market liquidity. As Amihud said: "In the market, liquidity is everything." (1980) In addition, the frequent occurrence of these financial visions also makes scholars question the traditional financial theory, especially the effective market hypothesis (Mandelbrot (1963), Mantegna and Stanley). At present, most studies on the spillover effects of stock volatility are based on the effective market hypothesis (EMH). However, Mandelbrot (1999) creatively proposed the fractal theory, then more and more studies (Peters (1991), Yuan and Zhuang (2008), He, et al (2014), Delbianco F, et al (2016), jiang ZQ, et al 
(2017)) showed that the complex nonlinear structure of the securities market is obvious fractal.

The main purpose of the launch of China stock index futures is not only to realize the diversification of trading varieties in the financial capital market and the effective prevention and control of risks, but also to meet the needs of investors' risk management. Therefore, the deep characteristics of liquidity fluctuations, and the liquidity spillover effects are particularly important. In fact, not just the stock market, the stock index futures market also does not meet the efficient market theory, the complex process of price change is the result of the combination of factors in different dimensions. Yin and Hua (2017), Tang and Zhu find that China's securities market, as well as CSI 300 index futures have multifractal characteristics, and there are significant differences in long memory and market risks. The so-called multifractal refers to an infinite set of different scaling indices on fractal structures, which is used to describe different scaling properties of the mass distribution over different regions. It has the characteristics of multiscale and the transition of scaling. As for multifractal research model, Peng, et al (1994) first proposed detrended fluctuation analysis (DFA), which is mainly used for long-range correlation analysis of time series. Trend components of all order in the sequence can be efficiently filtered, and long-range correlations containing noise and superimposed polynomial trend signals can be analyzed. However, this model can't be used to describe the multi-scale and fractal time series subset. On this basis, Kantelhardt, et al (2002) proposed multifractal detrended fluctuation model (MF-DFA). The use of multifractal to describe different levels of the fractal market enables not only to analyze the long-range correlations of non-stationary sequences, but also to avoid misjudgments (Norouzzadeh and Jafari).

Although a lot of existing researches have studied the fractal structure of the securities market and stock market volatility spillover, but we find that at present no one has been involved in the fields of the multifractal characteristics of liquidity and liquidity spillover effect between the stock index futures and spot. The traditional linear theory is difficult to deeply reveal the mechanism of fluctuations, and accurately predict its change trends. Therefore, this paper will study the liquidity spillover effect of stock index futures and spot market based on the fractal theory, aiming to answer the following questions: whether the fractal characteristics in liquidity of stock index futures and spot markets exist? What kind of impact will the maturity period have on the fractal degree of the liquidity of stock index futures contracts? Under the fractal market hypothesis (FMH), whether there is a spillover effect exists between the 
liquidity of stock index futures market and stock market? Whether the multifractal degree of market will influence this spillover effect?

Based on this, firstly, this paper uses the historical data of China stock index futures market and spot market, establishes the indicators of liquidity, tests the multifractal characteristics of China stock index futures market and spot market with the MF-DFA model, measures the multifractal degree and judges the causes of multifractal. Secondly, the influence of the multifractal degree on the correlation, spillover direction, strength, and contribution are studied respectively.

\section{Multifractal detrended fluctuation model (MF-DFA)}

It is assumed that a limited time sequence $\left\{x_{t}\right\}_{t=1}^{N}$ is given, and the length of the sequence is $N$. The steps of MF-DFA are as follows:

(1) Construct the cumulative discrepancy columns:

$$
X_{b}=\sum_{t=1}^{b}\left(x_{t}-\langle x\rangle\right), \quad b=1,2, \mathrm{~L}, N
$$

Among them, $\langle x\rangle$ is the mean of time sequences $\left\{x_{t}\right\}_{t=1}^{N}$.

(2) Equally space the column $\left\{x_{b}\right\}_{b=1}^{N}$, the length is $s$, remove the excess part, and $N_{s} \equiv \operatorname{int}(N / s) \quad$ subsequences can be obtained.

(3) Fit the partial trend of the No.m subsequence, resulting in the fluctuation equation without trend

$$
F^{2}(m, s)=\frac{1}{s} \sum_{i=1}^{s}\left[X_{(m-1) s+N-s N_{s}+i}-p_{m}(i)\right]^{2}
$$

Among them, $m=1,2, \mathrm{~L}, N_{s} \cdot p_{m}(i)$ is a linear trend function, the corresponding polynomial order is $L$.

(4) Calculate $q$ order fluctuations function

$$
\begin{cases}F_{q}(s)=\left\{\frac{1}{N_{s}} \sum_{m=1}^{N_{s}}\left[F^{2}(m, s)\right]^{\frac{q}{2}}\right\}^{\frac{1}{q}}, & q \neq 0 \\ F_{q}(s)=\exp \left\{\frac{1}{2 N_{s}} \sum_{m=1}^{N_{s}} \ln \left[F^{2}(m, s)\right]\right\}, & q=0\end{cases}
$$

(5) If a power law correlation exists between $F_{q}(s)$ and $s$, there is a relational expression 


$$
F_{q}(s) \sim s^{h(q)}
$$

Among them, $h(q)$ is the $q$ order generalized Hurst index and used to characterize the power-law correlations between the sequences. When $q=2$, it is a classic Hurst index. If there is no associated relationship between $h(q)$ and $q$, it indicates that the original time sequence $\left\{x_{t}\right\}_{t=1}^{N}$ has a single-shaped feature, on the contrary, it has a multifractal feature. When $h(q)<0.5$, the time series shows the characteristics of the inverse resistance, that is, when the time series of the current period is an upward trend, the probability of a decrease in the time sequence after a period of time is high; When $h(q)=0.5$, the time series obeys the random walk, that is, there is no cross-correlation;

When $h(q)>0.5$, there is a positive persistence in the time series, which is also known as long memory, that is, the current time series has an upward trend, then presents a rising trend.

It is known that the dimension $(\Delta h)$ of multifractal forms in the time series is shown:

$$
\Delta h=h\left(q_{\min }\right)-h\left(q_{\max }\right)
$$

Obviously, the larger the value of $\Delta h$, the larger the multifractal degree of the time series, and the volatility of the time series is also deviated from the random walk.

\section{Data source and related variables}

\subsection{Data source}

This paper takes China's CSI 300 stock index futures and CSI 300 index as the research object, in which CSI 300 index futures mainly have four kinds of contracts, such as IF00, IF01, IF02 and IF03, and also uses the data of 2724 trading days from April 16,2010 to June 30,2021. This paper studies the multifractal fluctuation characteristics of the market liquidity and the liquidity spillover effect between the stock index futures and spot. All data are from iFinD Financial Database.

\subsection{Indicator description}

In the indicators to measure the market liquidity, most scholars (Xu Y Y, et al (2019), Xiong, et al (2020)) often use the change rate, the buyer, the price difference and the Amihud non-liquidity indicator. Zhang, et al (2014) found that for low frequency data, 
the Amihud non-liquidity indicator perform better. Therefore, he Amihud non-liquidity indicator is selected in this paper $\left(H_{t}^{l}\right)$ to measure the liquidity of CSI 300 index futures and CSI 300 index, the specific calculation is as follows:

$$
H_{t}^{l}=\frac{\left|V_{t}\right|}{V o l_{t}}
$$

Among them, $H_{t}^{l}$ represents the liquidity of the stock index futures or spot in $t$-day; $V l_{t}$ is the volume of transaction at $t$-day, the unit is hand; $V_{t}$ represents the yield of $t$-day, and $V_{t}=\left(P_{\text {close }, t}-P_{\text {open }, t}\right) / P_{\text {open }, t}, \quad P_{\text {close }, t}$ and $P_{\text {open }, t}$ is the closing price and opening price of $t$-day respectively. Therefore, using the Amihud non-liquidity indicator, the liquidity of IF00, IF01, IF02 and IF03 in $t$-day can be expressed as $H_{f 1, t}^{1}, H_{f 2, t}^{1}, H_{f 3, t}^{1}$, $H_{f 4, t}^{1}$; the liquidity of CSI 300 index in $t$-day can be expressed as $H_{h, t}^{1}$.

In addition, some scholars have pointed out that there is an intrinsic relevance between the volume of transactions and liquidity, and the liquidity can also be reflected. Learning from Liu, et al (2013), Yu, et al (2016) and Liu, et al (2016), this paper uses the logarithm of trading volume as another indicator $H^{2}$. The formula is as follows:

$$
H_{t}^{2}=\ln \left(\text { Vol }_{t}\right)
$$

Among them, Vol $_{t}$ is the volume of transactions of CSI 300 index futures and CSI 300 index in $t$-day.

\section{Empirical Analysis}

\subsection{Descriptive statistics}

According to the formula (10) and formula (11), this paper obtains the descriptive statistical results of the liquidity $\left(H^{1}\right)$ of CSI 300 index futures and CSI 300 index, as shown in Table 1. As can be seen from Table 1, CSI 300 index futures and CSI 300 index significantly do not meet the assumptions of normal distribution, showing a significant asymmetric peak-tail feature. In addition, the ADF test is used to test the time series variable, and it is found that the liquidity of the stock index futures and spot are stable time series. At the same time, from the perspective of mean and standard deviation, the liquidity indicator (Amihud non-liquidity indicator) of CSI 300 index is significantly lower than CSI 300 index futures, and the fluctuations are smaller. In other words, compared with CSI 300 index futures, the stock index liquidity is better, and 
less volatile.

Table 1 The descriptive statistics of the liquidity of CSI 300 index futures and CSI 300 index $\left(H^{1}\right)$

\begin{tabular}{l|lllll}
\hline & $\operatorname{IF00}\left(H_{f 1, t}^{1}\right)$ & $\operatorname{IF01}\left(H_{f 2, t}^{1}\right)$ & $\operatorname{IF02}\left(H_{f 3, t}^{1}\right)$ & $\operatorname{IF03}\left(H_{f 4, t}^{1}\right)$ & CSI 300 index $\left(H_{h, t}^{1}\right)$ \\
\hline Mean & $2.15 \mathrm{E}-05$ & 0.0004 & 0.0005 & 0.0024 & $1.03 \mathrm{E}-08$ \\
Median & $5.74 \mathrm{E}-06$ & $7.06 \mathrm{E}-05$ & 0.0001 & 0.0008 & $6.68 \mathrm{E}-09$ \\
Max & 0.0011 & 0.0268 & 0.0202 & 0.0564 & $1.22 \mathrm{E}-07$ \\
Min & 0 & 0 & 0 & 0 & $5.50 \mathrm{E}-12$ \\
Std.Dev & $4.42 \mathrm{E}-05$ & 0.0013 & 0.0010 & 0.0048 & $1.13 \mathrm{E}-08$ \\
Skewness & 8.7580 & 8.5304 & 7.0604 & 5.3040 & 2.4890 \\
Kurtosis & 170.16 & 108.75 & 89.92 & 43.05 & 12.82 \\
Jarque- & & & & & $13768^{* * *}$ \\
Bera & $3206395^{* * *}$ & $1302281^{* * * *}$ & $880163^{* * *}$ & $194834^{* * *}$ & -6.28 \\
ADF test & $-4.49^{* * *}$ & $-10.55^{* * *}$ & $-7.06^{* * *}$ & $-4.74^{* * *}$ & -13 \\
\hline
\end{tabular}

$1 * * *$ represents to reject the original hypothesis under a $1 \%$ significance level.

This paper is based on liquidity indicator $H^{1}$ to draw the liquidity circular timing chart of CSI 300 index futures and CSI 300 index respectively, the results are shown in Fig.1 and Fig.2.
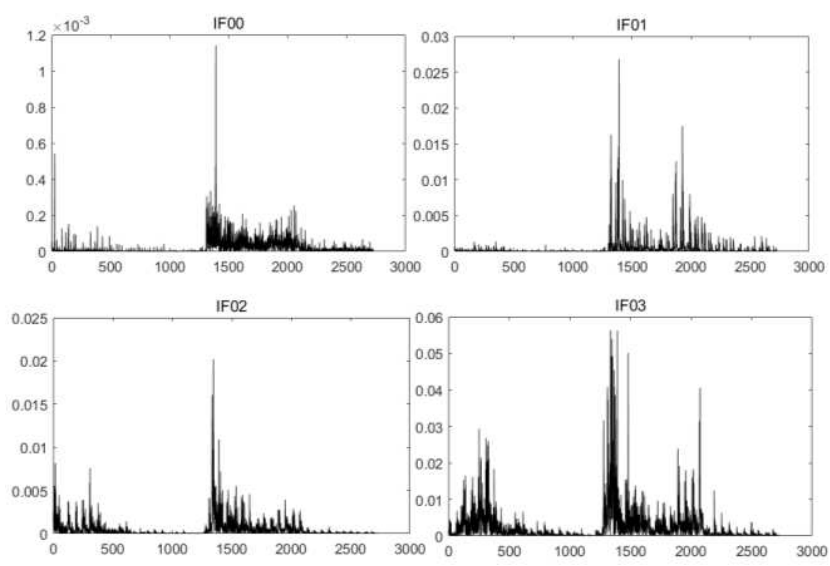

Fig.1 Circular timing chart of CSI 300 index futures $\left(H^{1}\right)$

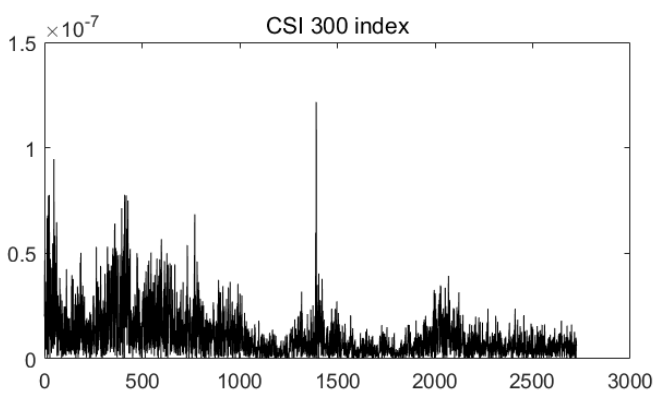

Fig.2 Circular timing chart of CSI 300 index $\left(H^{1}\right)$

The descriptive statistical results of the liquidity indicator $H^{2}$ are shown in Table 2 . 
It can be observed that the bias is not 0 , the peak degree is not 3 , and the accompanying probability of JB statistics is 0 , the sequence is stable and statistical characteristics. The descriptive statistical results of indicator $H^{2}$ is consistent with the indicator $H^{1}$.

Table 2 The descriptive statistics of the liquidity of CSI 300 index futures and CSI 300 index

\begin{tabular}{|c|c|c|c|c|c|}
\hline & $\begin{array}{l}\text { IF00 } \\
\left(H_{f 1, t}^{1}\right)\end{array}$ & $\begin{array}{l}\text { IF01 } \\
\left(H_{f 2, t}^{1}\right)\end{array}$ & $\begin{array}{l}\text { IF02 } \\
\left(H_{f 3, t}^{1}\right)\end{array}$ & $\begin{array}{l}\mathrm{IF} 03 \\
\left(H_{f 4, t}^{1}\right)\end{array}$ & $\begin{array}{l}\text { CSI } 300 \text { index } \\
\left(H_{h, t}^{1}\right)\end{array}$ \\
\hline Mean & 11.5048 & 9.1196 & 8.3419 & 6.6358 & 18.3632 \\
\hline Median & 11.4923 & 9.0731 & 8.2351 & 6.5132 & 18.3198 \\
\hline Max & 14.8741 & 14.6659 & 12.3921 & 11.0222 & 20.3470 \\
\hline Min & 8.1403 & 3.8067 & 4.9698 & 3.2958 & 16.9021 \\
\hline Std.Dev & 1.5942 & 1.8874 & 1.4795 & 1.3774 & 0.6157 \\
\hline Skewness & 0.0268 & 0.1788 & 0.1878 & 0.3584 & 0.4169 \\
\hline Kurtosis & 1.8339 & 2.8141 & 2.3006 & 2.7235 & 3.1329 \\
\hline Jarque-Bera & $154.6572 * * *$ & $18.4409 * * *$ & $71.5307 * * *$ & $67.0063 * * *$ & $80.9054 * * *$ \\
\hline ADF test & -1.6493 & $-4.5013 * * *$ & $-4.7202 * * *$ & $-4.8497 * * *$ & $-3.9869 * * *$ \\
\hline
\end{tabular}

$1 * * *$ represents to reject the original hypothesis under a $1 \%$ significance level.

Based on transaction volume to structure the liquidity indicator $H^{2}$, its corresponding circular timing chart of CSI 300 index futures and CSI 300 index are shown in Fig.3 and Fig.4.
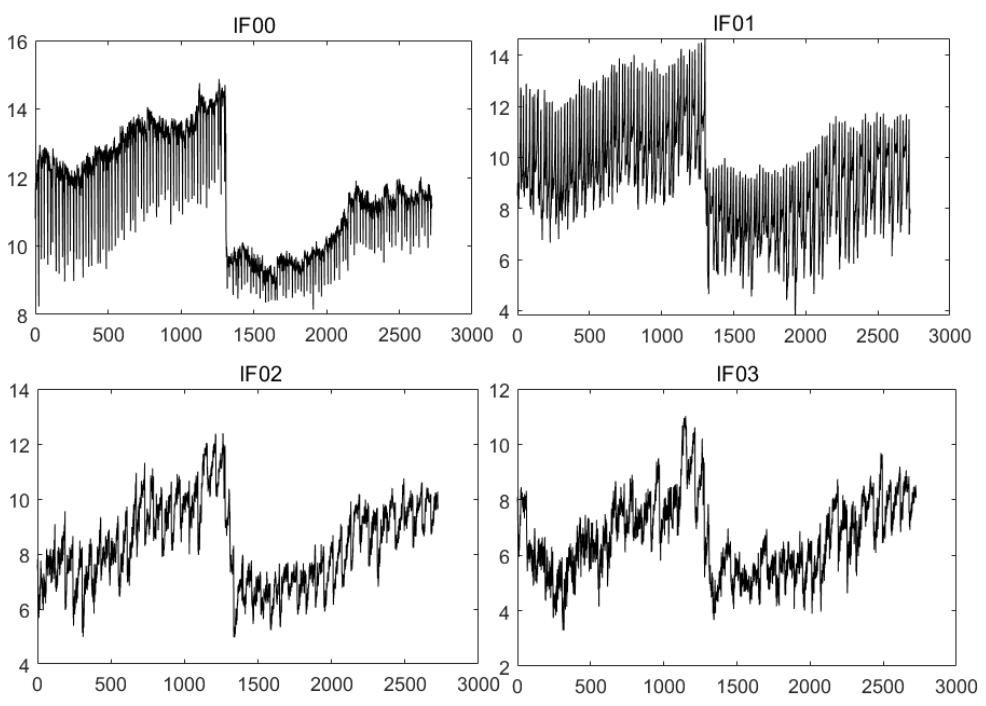

Fig.3 Circular timing chart of CSI 300 index futures $\left(H^{2}\right)$

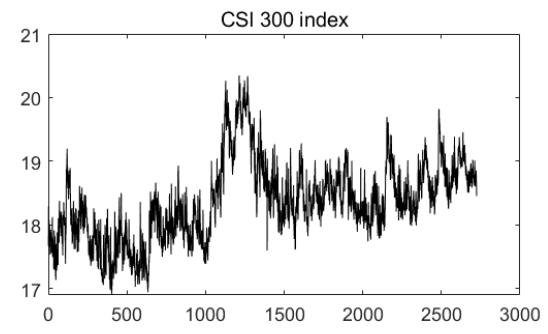


Fig.4 Circular timing chart of CSI 300 index $\left(H^{2}\right)$

\subsection{Multi - fractal test and cause analysis}

1 Multi - fractal test

This section uses the MF-DFA model to analyze the nonlinear fluctuation characteristics of the liquidity of CSI 300 index futures and CSI 300 index, as shown in Fig.5. Among them, except IF03, other contracts and CSI 300 index have smoothed nonlinear decreased trend and $h(q)$ is not a fixed constant, so they have obvious multifractal features, that is, no matter how the value $q$ changes, $h(q)$ always changes. It may be affected by factors such as the expiry period, IF03 do not show stable multifractal characteristics, and trading volume of IF03 accounts for a small percentage of total volume. Therefore, the liquidity spillover effect of IF00, IF01, IF02 and CSI 300 index with significant multifractal characteristics will be analyzed in the following part.

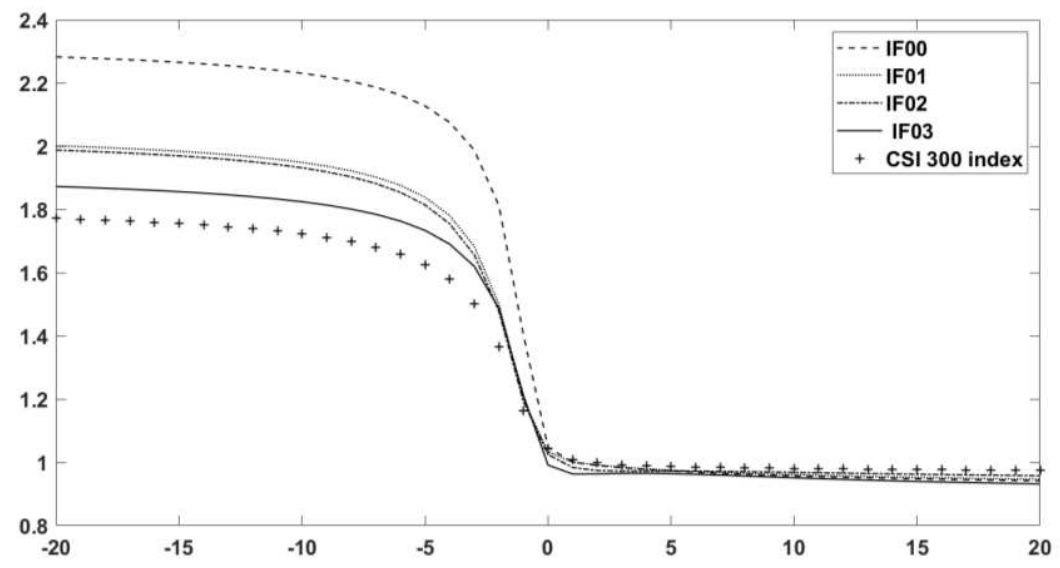

Fig.5 The multifractal characteristics of CSI 300 index futures and CSI 300 index $\left(H^{1}\right)$

When $q$ takes a specific value, the value of the evaluation scale index $h(q)$ and $\Delta h$ of CSI 300 index futures and CSI 300 index are showed in Table 3. As can be seen from Table 3, regardless of the value of $q, h(q)$ is greater than 0.5 , indicating that both small and big fluctuations in CSI 300 index futures market and CSI 300 index markets have long memory, that is, the past liquidity trends will affect the future liquidity trend. At the same time, the long-term memory of the stock index futures market is stronger than that of the spot market, which indicates that the liquidity changes in the stock index futures market have more persistent character, and it is not easy to reverse; secondly, the value of $\Delta \mathbf{h}$ in CSI 300 index futures is far greater than 
$\Delta \mathbf{h}$ in CSI 300 index, indicating that the multifractal degree of the stock index futures market is stronger than the spot market, that is, the liquidity of the stock index futures market is more complex and more deviated from random walk; Finally, the longer the expiry period of the stock index futures contract, the smaller the multifractal degree. This is because the longer the time, the greater the uncertainty of the future, the less susceptible the contract is to external manipulation, so the multifractal degree is smaller, and the contract is more biased towards the random change.

Table 3 The value of $h(q)$ and $\Delta h$ in CSI 300 index futures and CSI 300 index $\left(H^{1}\right)$

\begin{tabular}{lllllll}
\hline & $h(-2)$ & $h(-1)$ & $h(0)$ & $h(1)$ & $h(2)$ & $\Delta h$ \\
\hline IF00 & 1.81 & 1.40 & 1.05 & 1.00 & 0.99 & 0.82 \\
IF01 & 1.50 & 1.20 & 1.03 & 1.00 & 0.99 & 0.51 \\
IF02 & 1.48 & 1.19 & 1.02 & 0.98 & 0.97 & 0.51 \\
IF03 & 1.49 & 1.21 & 0.99 & 0.96 & 0.96 & 0.52 \\
CSI 300 index & 1.37 & 1.16 & 1.04 & 1.01 & 1.00 & 0.37 \\
\hline
\end{tabular}

2 Multifractal cause analysis

From the above research, it can be seen that both stock index futures and spot have significant multifractal characteristics, so what is the cause of the formation? In this question, this section will randomly disrupt CSI 300 index futures and CSI 300 index liquidity sequence, and analyze whether there are also multifractal characteristics and the causes of multifractal formation. Fig. 6 and Table 3 are multifractal features and values of $h(q)$ of the reset flow sequence. As can be seen from Fig. 6, the reset liquidity sequence still has significant multifractal characteristics. At the same time, it is known that the reset sequence also has obvious long-term memory, and the generalized Hurst indexes before and after reset are not equal. According to the multifractal theory, when $h(q)$ and $h^{T}(q)$ vary with the variation of $q$, if $h^{T}(q)=h(q)$, it indicates that the multifractal characteristics of the original time sequence is caused by only distributed multifractal characteristics; if $h^{T}(q) \neq h(q)$,it indicates that the multifractal characteristics of liquidity will be described by the correlated multifractal characteristics and distributed multifractal characteristics together. It can be obtained that the multifractal characteristics of CSI 300 index futures and CSI 300 index are caused by the correlated multifractal characteristics and distributed multifractal characteristics. 


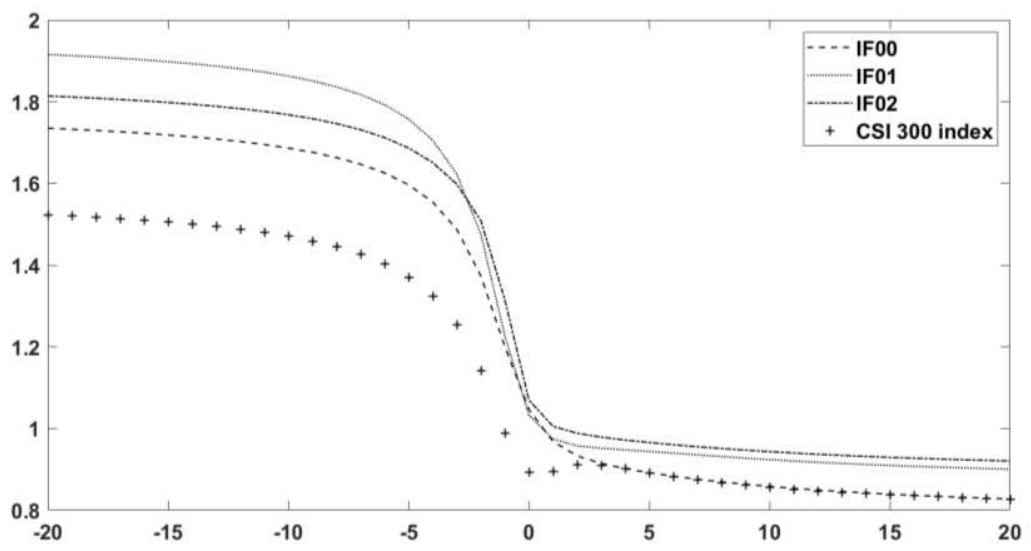

Fig.6 The multifractal characteristics of the reset liquidity sequence of CSI 300 index futures and CSI 300 index $\left(H^{1}\right)$

Table 3 The value of $h(q)$ and $h^{T}(q)$ in the reset liquidity sequence CSI 300 index futures and CSI 300 index $\left(H^{1}\right)$

\begin{tabular}{cccc}
\hline & $\mathrm{h}(2)$ & $\mathrm{h}^{\mathrm{T}}(2)$ & $\mathrm{h}(2)-\mathrm{h}^{\mathrm{T}}(2)$ \\
\hline IF00 & 0.99 & 0.93 & 0.06 \\
IF01 & 0.99 & 0.96 & 0.03 \\
IF02 & 0.97 & 0.99 & -0.01 \\
CSI 300 index & 1.00 & 0.91 & 0.09 \\
\hline
\end{tabular}

\subsection{Existence of the liquidity spillover effect in stock index futures and spot market}

According to the ADF test results above, CSI 300 index futures and CSI 300 index liquidity sequence are all stable time series. Therefore, it is possible to study the dynamic related relationship between CSI 300 index futures and CSI 300 index, and determine whether there is liquidity spillover effect.

This section utilizes the VAR model. First of all, we need judge the optimal lag order of CSI 300 stock index futures and CSI 300 index based on the Likelihood Ratio (LR), Final Prediction Error (FPE), Akaike Information Criterion (AIC), Schwarz Criterion (SC), and Hannan-Quinin Guidelines (HQ), then find that the optimal lag order is 8, and the VAR models are showed in Table 4.

Table 4 The dynamic related relationship between CSI 300 index futures and CSI 300 index $\left(H^{1}\right)$

\begin{tabular}{|c|c|c|c|c|c|c|c|c|}
\hline & F1 & $\mathbf{H}$ & & F2 & $\mathbf{H}$ & & F3 & $\mathbf{H}$ \\
\hline \multirow[t]{2}{*}{ F1(-1) } & $0.07 * * *$ & -0.00 & F2(-1) & $0.27 * * *$ & $-0.00 * * *$ & F3(-1) & $0.22 * * *$ & $-0.00 * * *$ \\
\hline & $(3.40950)$ & $(-1.31925)$ & & (13.4139) & $(-2.63466)$ & & (10.4821) & $(-2.82295)$ \\
\hline F1(-2) & $0.09 * * *$ & 0.00 & F2(-2) & $0.26^{* * *}$ & -0.00 & F3(-2) & $0.24 * * *$ & 0.00 \\
\hline
\end{tabular}




\begin{tabular}{|c|c|c|c|c|c|c|c|c|}
\hline & (4.30523) & $(0.39323)$ & & (12.5968) & $(-0.31700)$ & & (11.2747) & $(0.09605)$ \\
\hline \multirow[t]{2}{*}{ F1(-3) } & $0.16^{* * *}$ & -0.00 & F2(-3) & $0.18 * * *$ & 0.00 & F3(-3) & $0.08 * * *$ & -0.00 \\
\hline & (7.77334) & $(-1.34894)$ & & $(8.43944)$ & $(0.95890)$ & & $(3.56585)$ & $(-0.95080)$ \\
\hline \multirow[t]{2}{*}{ F1(-4) } & $0.10 * * *$ & -0.00 & F2(-4) & $0.09 * * *$ & 0.00 & F3(-4) & 0.01 & 0.00 \\
\hline & $(4.62642)$ & $(-0.87569)$ & & $(4.20498)$ & $(1.30254)$ & & $(0.33002)$ & (1.61140) \\
\hline \multirow[t]{2}{*}{ F1(-5) } & $0.12^{* * *}$ & 0.00 & F2(-5) & $-0.08 * * *$ & 0.00 & F3(-5) & $0.15^{* * *}$ & 0.00 \\
\hline & $(5.46166)$ & $(0.60311)$ & & $(-3.63478)$ & $(0.16962)$ & & $(6.87993)$ & $(0.98577)$ \\
\hline \multirow[t]{2}{*}{ F1(-6) } & $0.10^{* * *}$ & 0.00 & F2(-6) & $-0.04 *$ & -0.00 & F3(-6) & $0.04^{*}$ & -0.00 \\
\hline & $(4.96426)$ & $(0.07926)$ & & $(-1.81161)$ & $(-0.63135)$ & & (1.70508) & $(-0.24387)$ \\
\hline \multirow[t]{2}{*}{ F1(-7) } & $0.10^{* * *}$ & -0.00 & F2(-7) & $0.06^{* * *}$ & 0.00 & F3(-7) & $0.04^{*}$ & 0.00 \\
\hline & $(4.70701)$ & $(-0.60625)$ & & $(2.77866)$ & (1.11175) & & (1.67433) & $(0.32962)$ \\
\hline \multirow[t]{2}{*}{ F1(-8) } & $0.05^{* *}$ & -0.00 & F2(-8) & $-0.05^{* *}$ & $-0.00 * *$ & F3(-8) & $0.06^{* * *}$ & -0.00 \\
\hline & (2.24654) & $(-1.06320)$ & & $(-2.56872)$ & $(-2.25235)$ & & $(2.82109)$ & $(-0.02831)$ \\
\hline \multirow[t]{2}{*}{ H(-1) } & $-193.04 * *$ & $0.07 * * *$ & $\mathbf{H}(-1)$ & $-9341.71 * * *$ & $0.07 * * *$ & $\mathbf{H}(-1)$ & $-9643.99 * * *$ & $0.08 * * *$ \\
\hline & $(-2.38465)$ & $(3.23324)$ & & $(-4.31861)$ & $(3.71287)$ & & $(-5.54183)$ & (4.02879) \\
\hline \multirow[t]{2}{*}{$\mathbf{H}(-2)$} & -37.31 & $0.05^{* *}$ & $\mathbf{H}(-2)$ & $-5647.13 * * *$ & $0.06^{* * *}$ & $\mathbf{H}(-2)$ & $-5220.68 * * *$ & $0.05 * *$ \\
\hline & $(-0.46275)$ & $(2.37129)$ & & $(-2.60427)$ & $(2.90332)$ & & $(-2.97212)$ & $(2.52821)$ \\
\hline \multirow[t]{2}{*}{ H(-3) } & 102.90 & $0.14^{* * *}$ & $\mathbf{H}(-3)$ & 901.91 & $0.12 * * *$ & $\mathbf{H}(-3)$ & $3348.54^{*}$ & $0.14 * * *$ \\
\hline & (1.28066) & $(6.65231)$ & & $(0.41617)$ & (6.31112) & & (1.90607) & $(6.67081)$ \\
\hline \multirow[t]{2}{*}{ H(-4) } & 53.63 & $0.11 * * *$ & $\mathbf{H}(-4)$ & -2349.59 & $0.10^{* * *}$ & $\mathbf{H}(-4)$ & 1978.45 & $0.09 * * *$ \\
\hline & $(0.66468)$ & $(5.12501)$ & & $(-1.07982)$ & $(4.90247)$ & & $(1.12121)$ & $(4.24281)$ \\
\hline \multirow[t]{2}{*}{ H(-5) } & $-167.73^{* *}$ & $0.08 * * *$ & $\mathbf{H}(-5)$ & 3413.88 & $0.08 * * *$ & $\mathbf{H}(-5)$ & -2287.01 & $0.08 * * *$ \\
\hline & $(-2.07897)$ & (3.65369) & & (1.56884) & $(4.27617)$ & & $(-1.29890)$ & $(3.69270)$ \\
\hline \multirow[t]{2}{*}{ H(-6) } & -80.84 & $0.09 * * *$ & $\mathbf{H}(-6)$ & 1683.33 & $0.09^{* * *}$ & $\mathbf{H}(-6)$ & 652.21 & $0.09 * * *$ \\
\hline & $(-1.00695)$ & (4.16963) & & $(0.77674)$ & (4.68999) & & $(0.37152)$ & $(4.47445)$ \\
\hline \multirow[t]{2}{*}{ H(-7) } & $-152.84 *$ & $0.12 * * *$ & $\mathbf{H}(-7)$ & 906.73 & $0.10^{* * *}$ & $\mathbf{H}(-7)$ & $3215.05^{*}$ & $0.11 * * *$ \\
\hline & $(-1.90135)$ & $(5.62763)$ & & $(0.41915)$ & $(5.32878)$ & & $(1.83714)$ & $(5.22246)$ \\
\hline \multirow[t]{2}{*}{ H(-8) } & 83.72 & $0.15^{* * *}$ & $\mathbf{H}(-8)$ & 1677.95 & $0.16^{* * *}$ & $\mathbf{H}(-8)$ & $3613.73 * *$ & $0.15 * * *$ \\
\hline & (1.03565) & (7.18549) & & $(0.77816)$ & (8.08166) & & (2.08237) & (7.11635) \\
\hline \multirow[t]{2}{*}{$\mathbf{C}$} & $0.00 * * *$ & $0.00 * * *$ & $\mathbf{C}$ & $0.00 * * *$ & $0.00 * * *$ & C & $0.00 * * *$ & $0.00 * * *$ \\
\hline & (5.99822) & $(7.12171)$ & & $(5.68535)$ & $(6.50883)$ & & $(4.27470)$ & (6.29555) \\
\hline
\end{tabular}

${ }^{1}$ T-statistics in parentheses.

$2 * * *, * *, *$ represents to reject the original hypothesis under a $1 \%, 5 \%$ and $10 \%$ significance level.

According to the VAR model, it can be seen from the results of CSI 300 index futures and CSI 300 index: 
First, CSI 300 index has a one-way liquidity spillover effect to the stock index futures. In the current period, the IF00 liquidity is significantly positively affected by its own lag period 1 to 8 , and also by the significant negative impact of lag period 1 and 5 of the CSI 300 index, it shows that the IF00 liquidity is mainly adjusted according to its own past liquidity, and affected by the CSI 300 Index to a lesser extent. In addition, the current liquidity of the CSI 300 index is only significantly positively affected by its own lag periods;

Second, there is a two-way liquidity spillover effect between IF01 and CSI 300 index. In the current period, IF01 liquidity is significantly affected by its lag periods except lag period 6, while the liquidity of the CSI 300 index in lag period 1 and 2 has a significant negative impact on IF01, it shows that IF01 liquidity is adjusted according to its own past liquidity, and affected by the liquidity lag periods of the CSI 300 index. At the same time, the liquidity of CSI 300 index is subject to the significant positive impact of its own past liquidity and the significant negative impact of IF01 in lag period 1 and 8;

Third, there is a two-way liquidity spillover effect between next IF02 and CSI 300 index quarter. The current IF02 liquidity is significantly affected by its other lag periods except lag period 6, while the liquidity of the CSI 300 index in lag period 1, 2 has a significant negative impact on IF02, it shows that the IF02 liquidity will be adjusted according to its own past liquidity, while being affected by the liquidity lag periods of the CSI 300 index. At the same time, the liquidity of CSI 300 index will be subject to the significant positive impact of all lag period of their own liquidity and the significant negative impact of IF01 in lag period 1;

To sum up, there is a significant liquidity spillover effect between CSI 300 index futures and CSI 300 index. The longer the maturity period of the futures contract, that is, the lower the multifractal degree, the more significant the liquidity spillover effect between them.

\subsection{The direction of the liquidity spillover effect}

The above studies have shown that there is a significant liquidity spillover effect between CSI 300 index futures and CSI 300 index, in this part, the Grander causality test is used to analyze the direction of liquidity spillover effect. Considering that different lag period can cause resulting errors, the lag period is selected as the same in the VAR model, that is 8 . The Grange causal test results are shown in Table 5.

Table 5 The direction of the liquidity spillover effect $\left(H^{1}\right)$ 


\begin{tabular}{lll}
\hline Null Hypothesis: & F-Statistic & Prob \\
\hline CSI 300 index does not Granger Cause IF00 & 3.4464 & 0.0006 \\
IF00 does not Granger Cause CSI 300 index & 1.9272 & 0.0520 \\
CSI 300 index does not Granger Cause IF01 & 4.3328 & $3.00 \mathrm{E}-05$ \\
IF01 does not Granger Cause CSI 300 index & 1.9380 & 0.0505 \\
CSI 300 index does not Granger Cause IF02 & 6.6470 & $1.00 \mathrm{E}-08$ \\
IF02 does not Granger Cause CSI 300 index & 1.6898 & 0.0958 \\
\hline
\end{tabular}

It can be seen from the table, CSI 300 index have a clear one-way liquidity spillover effect to CSI 300 index futures, while the effect from CSI 300 index futures to CSI 300 index is not significant. In the above section, using the VAR model can also prove that there is a significant liquidity spillover effect, which explains that the significance of the corresponding coefficient of the CSI 300 index in the VAR model of the CSI 300 stock index futures is much greater than that of CSI 300 index futures in the CSI 300 index, so the conclusion of Granger causality test and the regression result of the VAR model are basically consistent.

\subsection{Intensity of the liquidity spillover effect}

The following uses the impulse response function to verify the intensity of the liquidity spillover effect from the spot to stock index futures. First, the root of the AR is used to perform a stationary test. It is found that the roots of the model obviously locate in the unit circle, indicating that they are stable.

The results of the impulse response function are shown in Fig.7. As can be seen from the figure, the liquidity spillover effect of the spot to stock index futures is positive, and the impact has a long time. As the expiry period of the stock index futures grows, the intensity has increased, that is, the contracts' expiry period and the intensity spillover intensity are proportional. In addition, the expiry period of the stock index futures contract is inversely proportional to the multifractal degree, so it is true that the spillover intensity is inversely proportional to the degree of multifractal. The above conclusions can be explained that the lower the multifractal degree of the market, the closer to the random walk distribution, thus fluctuating becomes more unpredictable, 'and market volatility cannot be controlled and reduced in advance, and the larger volatility means that the greater intensity of liquidity spillover across markets. 


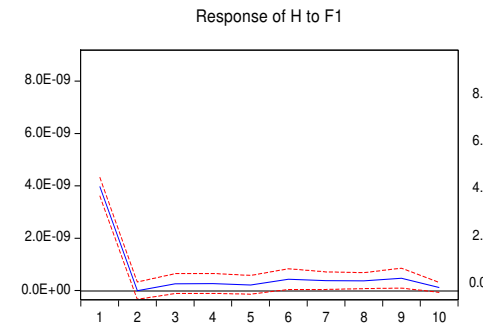

(a)

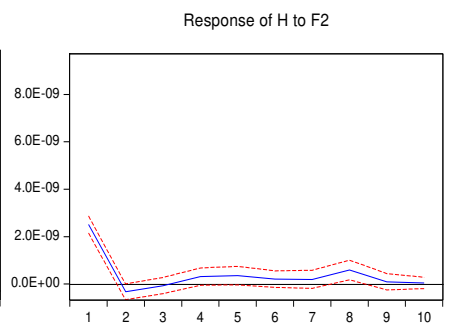

(b)

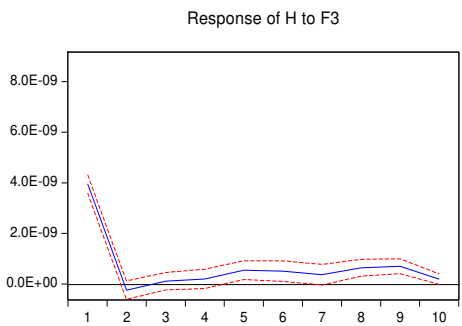

(c)

Fig.7 The intensity of the liquidity spillover effect from CSI 300 index to CSI 300 index futures $\left(H^{1}\right)$

\subsection{Contribution to liquidity spillover effect}

This paper further utilizes Hasbrouck variance decomposition to analyzes the difference of the contribution of CSI 300 index to the liquidity spillover effect of stock index futures contract with different maturities. The variance decomposition results are shown in Table 6.

Table 6 The contribution of CSI 300 index in the liquidity spillover effect of CSI 300 index future

$$
\left(H^{1}\right)
$$

\begin{tabular}{llllllllll}
\hline \multicolumn{3}{c}{ Variance Decomposition of F1: } & \multicolumn{3}{c}{ Variance Decomposition of F2: } & \multicolumn{3}{c}{ Variance Decomposition of F3: } \\
Period & S.E. & F1 & H & S.E. & F2 & H & S.E. & F3 & H \\
\hline 1 & $3.79 \mathrm{E}-05$ & 100.00 & 0.00 & $1.07 \mathrm{E}-03$ & 100.00 & 0.00 & $8.14 \mathrm{E}-04$ & 100.00 & 0.00 \\
2 & $3.79 \mathrm{E}-05$ & 99.79 & 0.21 & $1.11 \mathrm{E}-03$ & 99.37 & 0.63 & $8.30 \mathrm{E}-04$ & 98.93 & 1.07 \\
3 & $3.81 \mathrm{E}-05$ & 99.77 & 0.23 & $1.16 \mathrm{E}-03$ & 98.91 & 1.09 & $8.60 \mathrm{E}-04$ & 98.28 & 1.72 \\
4 & $3.87 \mathrm{E}-05$ & 99.76 & 0.24 & $1.22 \mathrm{E}-03$ & 98.86 & 1.14 & $8.75 \mathrm{E}-04$ & 98.30 & 1.70 \\
5 & $3.91 \mathrm{E}-05$ & 99.76 & 0.24 & $1.26 \mathrm{E}-03$ & 98.46 & 1.54 & $8.82 \mathrm{E}-04$ & 98.25 & 1.75 \\
6 & $3.95 \mathrm{E}-05$ & 99.54 & 0.46 & $1.27 \mathrm{E}-03$ & 98.37 & 1.63 & $9.03 \mathrm{E}-04$ & 98.02 & 1.98 \\
7 & $4.00 \mathrm{E}-05$ & 99.46 & 0.54 & $1.29 \mathrm{E}-03$ & 98.29 & 1.71 & $9.13 \mathrm{E}-04$ & 97.89 & 2.11 \\
8 & $4.05 \mathrm{E}-05$ & 99.23 & 0.77 & $1.30 \mathrm{E}-03$ & 98.23 & 1.77 & $9.27 \mathrm{E}-04$ & 97.91 & 2.09 \\
9 & $4.09 \mathrm{E}-05$ & 99.23 & 0.77 & $1.30 \mathrm{E}-03$ & 98.15 & 1.85 & $9.44 \mathrm{E}-04$ & 97.97 & 2.03 \\
10 & $4.11 \mathrm{E}-05$ & 99.14 & 0.86 & $1.31 \mathrm{E}-03$ & 98.04 & 1.96 & $9.52 \mathrm{E}-04$ & 97.82 & 2.18 \\
\hline
\end{tabular}

As can be seen from the table, the contribution of CSI 300 index futures in CSI 300 index has gradually increased as the maturity increased, that is, IF00, IF01 and IF02 increase in turn. The variance decomposition considers the proportion of the spot in the total variance of the stock index futures, and the liquidity risk is measured by the variance of liquidity indicators, which is equivalent to the contribution of the spot to the liquidity risk of the stock index futures. The results show that the contribution of spot is inversely proportional to the multifractal degree. Possible cause is that the higher 
the multifractal degree is, the less the market changes fit the random walk in the effective market hypothesis, and this improves the investor or government's predictive effeciency on future liquidity risk infection, so they can take the corresponding measures in advance to inhibit negative effects. In CSI 300 index futures, due to the most predictability of IF00, it is possible to lock in its liquidity risk sources in advance, namely CSI 300 index, and reduce the infection strength of CSI 300 index.

\section{Robustness test}

In order to verify the effectiveness of the above conclusion, the liquidity indicator $H^{2}$ is used for a robustness test. First, the multifractal characteristics and degree of CSI 300 index futures and CSI 300 index are verified according to the MF-DFA method, and the results are shown in Fig. 8 and Table 7. It can be seen that IF00, IF01, IF02 and CSI 300 index have significant multifractal characteristics, and the complexity of the stock index futures is much larger than the spot.

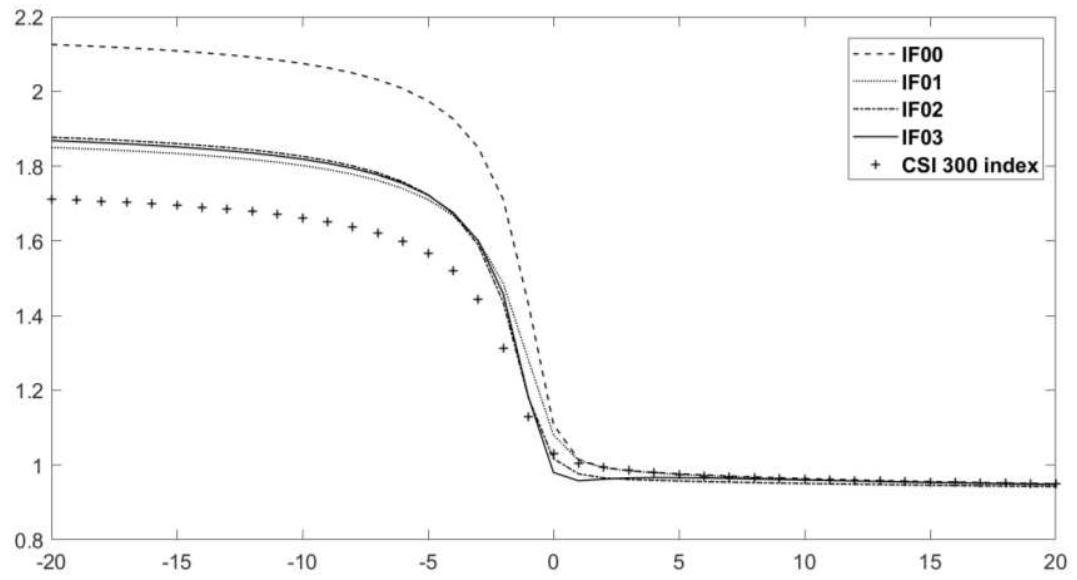

Fig.8 The multifractal characteristics of CSI 300 index futures and CSI 300 index

Table 7 The value of $h(q)$ and $\Delta h$ of CSI 300 index futures and CSI 300 index $\left(H^{2}\right)$

\begin{tabular}{lllllll}
\hline & $\mathrm{h}(-2)$ & $\mathrm{h}(-1)$ & $\mathrm{h}(0)$ & $\mathrm{h}(1)$ & $\mathrm{h}(2)$ & $\Delta \mathrm{h}$ \\
\hline IF00 & 1.71 & 1.43 & 1.11 & 1.01 & 0.99 & 0.72 \\
IF01 & 1.49 & 1.28 & 1.08 & 1.01 & 0.99 & 0.49 \\
IF02 & 1.44 & 1.18 & 1.02 & 0.98 & 0.97 & 0.47 \\
IF03 & 1.46 & 1.18 & 0.98 & 0.96 & 0.96 & 0.50 \\
CSI 300 index & 1.31 & 1.13 & 1.03 & 1.00 & 0.99 & 0.32 \\
\hline
\end{tabular}

Table 8 shows the Granger causality test under liquidity indicator $H^{2}$. It can be seen from the table that CSI 300 index has a unidirectional liquidity spillover effect on CSI 300 index futures.

Table 8 The direction of the liquidity spillover effect between CSI 300 index futures and CSI 300 index $\left(\mathrm{H}^{2}\right)$ 


\begin{tabular}{lll}
\hline Null Hypothesis: & F-Statistic & Prob \\
\hline CSI 300 index does not Granger Cause IF00 & 2.2286 & 0.0229 \\
IF00 does not Granger Cause CSI 300 index & 0.9396 & 0.4822 \\
CSI 300 index does not Granger Cause IF01 & 6.3132 & $4.00 \mathrm{E}-08$ \\
IF01 does not Granger Cause CSI 300 index & 0.5673 & 0.8055 \\
CSI 300 index does not Granger Cause IF02 & 14.2440 & $2.00 \mathrm{E}-20$ \\
IF02 does not Granger Cause CSI 300 index & 0.7233 & 0.6711 \\
\hline
\end{tabular}

Fig.9 shows the impulse response function of the liquidity indicator $H^{2}$, it can be seen that as the liquidity spillover party, the CSI 300 index has a significant positive relationship between the contract expiry period and the spillover intensity, that is, as the contract expiry period of stock index futures grows, its spillover intensity also increases.

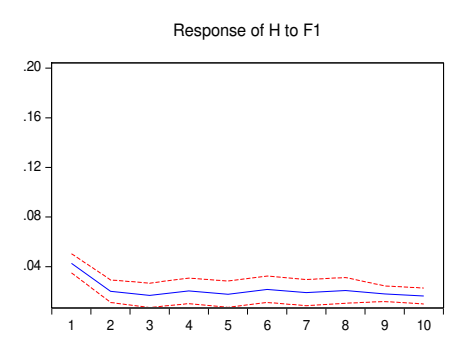

(a)

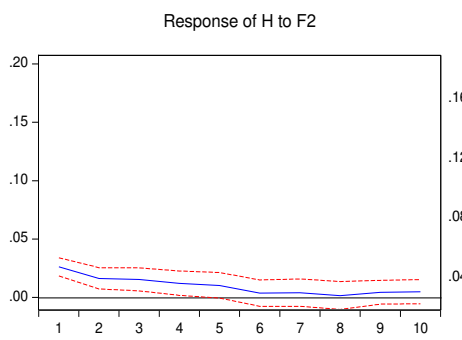

(b)

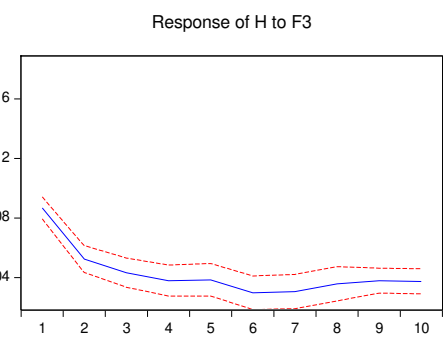

(c)

Fig.9 The intensity of the liquidity spillover effect from CSI 300 index to CSI 300 index futures

$$
\left(H^{2}\right)
$$

It can be seen from Table 9 that the liquidity spillover contribution of the CSI 300 index to the CSI 300 index futures increases with the increase of the contract expiry period, that is, the liquidity contribution of the spot to the stock index futures is inversely proportional to the multifractal degree.

Table 9 The contribution of CSI 300 index in the liquidity spillover effect of CSI 300 index future

$\left(H^{2}\right)$

\begin{tabular}{llllllllll}
\hline & \multicolumn{3}{c}{ Variance Decomposition of F1: } & \multicolumn{3}{c}{ Variance Decomposition of F2: } & \multicolumn{3}{c}{ Variance Decomposition of F3: } \\
Period & S.E. & F1 & H & S.E. & F2 & H & S.E. & F3 & H \\
\hline 1 & 0.51 & 100.00 & 0.00 & 0.92 & 100.00 & 0.00 & 0.38 & 100.00 & 0.00 \\
2 & 0.62 & 99.80 & 0.20 & 1.25 & 99.36 & 0.64 & 0.47 & 97.41 & 2.59 \\
3 & 0.66 & 99.79 & 0.21 & 1.44 & 99.45 & 0.55 & 0.54 & 96.91 & 3.09 \\
4 & 0.69 & 99.77 & 0.23 & 1.55 & 99.52 & 0.48 & 0.59 & 96.62 & 3.38 \\
5 & 0.71 & 99.74 & 0.26 & 1.62 & 99.55 & 0.45 & 0.64 & 96.64 & 3.36 \\
6 & 0.72 & 99.73 & 0.27 & 1.67 & 99.55 & 0.45 & 0.68 & 96.27 & 3.73 \\
7 & 0.74 & 99.74 & 0.26 & 1.71 & 99.57 & 0.43 & 0.73 & 96.30 & 3.70
\end{tabular}




\begin{tabular}{llllllllll}
8 & 0.76 & 99.75 & 0.25 & 1.74 & 99.59 & 0.41 & 0.76 & 96.22 & 3.78 \\
9 & 0.79 & 99.75 & 0.25 & 1.76 & 99.60 & 0.40 & 0.79 & 96.29 & 3.71 \\
10 & 0.82 & 99.74 & 0.26 & 1.78 & 99.60 & 0.40 & 0.82 & 96.30 & 3.70 \\
\hline
\end{tabular}

In summary, whether it is multifractal characteristics, or the existence of the liquidity spillover effects, spillover direction, intensity, and contribution, the result of the new liquidity indicator $H^{2}$ is consistent with the above research, it shows that this study has great robustness.

\section{Conclusion}

In recent years, there have been many extreme events such as Guangda Group 8.16 incident, China stock market crash in 2016, significantly affecting investors and market regulatory authorities, and posed a serious challenge to traditional effective market hypothesis. In this context, this paper uses the fractal market hypothesis, combined with CSI 300 index futures and CSI 300 index in China, first tests whether China stock index futures and spot market meet the effective market hypothesis; secondly, using the MFADF model to confirm that CSI 300 index futures and CSI 300 index have significant multifractal characteristics, and the financial market has more complex non-normal distribution. CSI 300 index futures have high multifractal degree, the multifractal degree is inversely proportional to the contracts' expiry period; then, using the VAR model, Granger causality test, impulse response functions and variance decomposition to prove the existence of the liquidity spillover effects, spillover direction, intensity, and contribution. Research finds: there is a significant asymmetric liquidity spillover effect between the stock index futures market and spot market, and the spillover strength and contribution are significantly affected by multifractal characteries; the intensity of liquidity overflow is proportional to the expiry period of the stock index futures contract, but inversely proportional to the multifractal degree of the stock index futures contract; the contribution of the spot is inversely proportional to the multifractal degree. Finally, the robustness test indicates a good robustness in this study. The relevant research results can not only contribute to a deeper understanding of the liquidity relationship between the stock index futures and spot theoretically, but also provide guidance for investors' investment practice and decision-making reference for the daily supervision of the construction and management departments.

\section{Acknowledgements}


This work is supported by the National Natural Science Foundation of China (71903017) and National Social Science Foundation of China (17BJY188).

\section{Data Availability Statement}

The data that support the findings of this study are available in iFinD Financial Database at http://www.51ifind.com.

\section{Declaration of interest statement}

The author declare that they have no financial and personal relationships with other people or organizations that could have appeared to influence the work reported in this paper.

\section{References}

[1] Harris L. S\&P 500 Cash Stock Price Volatilities[J]. Journal of Finance, 1989, 44(5): 1155-1175.

[2] Brorsen B W. Futures trading, transaction costs, and stock market volatility[J]. Journal of Futures Markets, 1991, 11(2): 153-163.

[3] Kamara, Jr T, Siegel A F. The effect of futures trading on the stability of standard and poor 500 returns[J]. Journal of Futures Markets, 1992, 12(6): 645-658.

[4] Bae S C, Kwon T H, Park J W. Futures trading, spot market volatility, and market efficiency: The case of the Korean index futures markets[J]. Journal of Futures Markets, 2004, 24(12): 1195-1228.

[5] Kittiakarasakun J, Tse Y, Wang G. The impact of trades by traders on asymmetric volatility for Nasdaq-100 index futures[J]. Managerial Finance, 2013, 38(8)

[6] Zhou Q L, Zhu Y J, Jia L X. Probability of informed trading, liquidity and volatility: evidence from China's stock index futures market[J]. Journal of Financial Research, 2015, (5): 132-147.

[7] Tu Z Y and Guo M. Stock index futures launched a theoretical analysis on the price impact of the spot market[J]. Journal of Financial Research, 2008, (10): 104-116.

[8] Kasman A, Kasman S. The impact of futures trading on volatility of the underlying asset in the Turkish stock market[J]. Physica A Statistical Mechanics \& Its Applications, 2008, 387(12): 2837-2845.

[9] Bessembinder H, Seguin P J. Futures-Trading Activity and Stock Price Volatility[J]. Journal of Finance, 2012, 47.

[10] Li J L, Lei Y, Li S J. Market depth, liquidity and volatility — The impact of the CSI 300 index futures launch on the spot market[J]. Journal of Financial Research, 2012, (6): 124-138.

[11] Zong J C and Li X Y. Stock index futures launched the impact analysis on the spot market - 
— empirical research based on macro variables elimination[J]. Macroeconomics

[12] Dai F X and Yin L B. Can stock index futures improve market efficiency? [J]. Finance \& Trade Economics, 2013, (1): 73-79.

[13] Cao D and Zhang J. The impact of index future on stock market volatility based on the GARCH-M model[J]. Chinese Journal of Management Science, 2017, 25(1): 27-34.

[14] Edwards F R. Does Futures Trading Increase Stock Market Volatility? [J]. Financial Analysts Journal, 1988, 44(1): 63-69.

[15] Antoniou A, Holmes P, Priestley R. The effects of stock index futures trading on stock index volatility: An analysis of the asymmetric response of volatility to news[J]. Journal of Futures Markets, 1998, 18.

[16] Darrat A F, Rahman S, Zhong M. On the Role of Futures Trading in Spot Market Fluctuations: Perpetrator of Volatility or Victim of Regret? [J]. Journal of Financial Research, 2010, 25(3): 431-444.

[17] Tan R Y and Sheng M N. Will stock index future affect the volatility of stock market? [J]. Contemporary Finance \& Economics, 2011, (10): 56-64.

[18] Xiong X, Liu J, Xu H C, et al. Analyzing the impact on stock index futures market volatility of arbitrage[J]. Systems Engineering-Theory \& Practice, 2014, 34(3): 623-630.

[19] Bohl M T, Diesteldorf J, Siklos P L. The effect of index futures trading on volatility: Three markets for Chinese stocks[J]. China Economic Review, 2015.

[20] Amihud Y, Mendelson H. Dealership market: Market-making with inventory[J]. Journal of Financial Economics, 1980, 8(1): 31-53.

[21] Mandelbrot B B. The Variation of Certain Speculative Prices[J]. The Journal of Business, 1963, 36(4): 394-394.

[22] Mantegna R N, Stanley H E. Scaling behaviour in the dynamics of an economic index[J]. Nature.

[23] Mandelbrot B A. Multifractal walk down wall street[J]. Scientific American, 1999, 280(2): 7073.

[24] Peters E E. Chaos and order in the capital markets[M]. New York: Wiley, 1991.

[25] Yuan Y, Zhuang X T. Multifractal description of stock price index fluctuation using a quadratic function fitting[J]. Physica A: Statistical Mechanics and its Applications, 2008, 387(2-3): 511518.

[26] He X L, Wang H W, Du Z P. The complexity and fractal structures of CSI300 before and after the introduction of CSI300IF[J]. Physica A: Statistical Mechanics and its Applications, 2014, 414: 76-85.

[27] Delbianco F, Tohmé F, Stosic T, et al. Multifractal behavior of commodity markets: Fuel versus 
non-fuel products[J]. Physica A: Statistical Mechanics and its Applications, 2016, 457: 573580.

[28] Jiang Z Q, Yang Y H, Wang G J, et al. Joint multifractal analysis based on wavelet leaders[J]. Frontiers of Physics, 2017, 12(6): 128907.

[29] Yin H Y and Hua Y P. Study on the nonlinear dynamic characteristics of stock market liquidity in China-a test based on fractal theory[J]. Management Review, 2017, 29(8): 43-52.

[30] Tang Y, Zhu P F. Portfolio strategies of Shanghai \& Hong Kong stock markets from the perspective of fractal theory[J]. Systems Engineering-Theory \& Practice, 2018, 38(9): 21882201.

[31] Peng C K, Buldyrev S V, Havlin S, et al. Mosaic organization of DNA nucleotides[J]. Physical Review E, 1994, 49(2): 1685-1689.

[32] Kantelhardt J W, Zschiegner S A, Bunde E K, et al. Multifractal detrended fluctuation analysis of nonstationary time series[J]. Physica A, 2002, 316(1): 87-114.

[33] Norouzzadeh P, Jafari G R. Application of multifractal measures to Tehran price index[J]. Physica A: Statistical Mechanics and its Applications, 2005, 356(2): 609-627.

[34] Xu Y Y, Huang D S, Ma F, et al. Liquidity and realized range-based volatility forecasting: Evidence from China[J]. Physica A: Statistical Mechanics and its Applications, 2019, 525: 1102-1113.

[35] Xiong X, Xu K W, Shen D H. Investor sentiment and futures market functions: evidence from CSI300 index futures market[J]. Systems Engineering-Theory \& Practice, 2020, 40(9): 22522268.

[36] Zheng Z, Yi Z L, Yu L Z, et al. A test on indirect liquidity measures in China stock market: an empirical analysis of the direct and indirect measures of bid-ask spread[J]. China Economic Quarterly, 2014, 13(1): 233-262.

[37] Liu X L and Wang S Y. The intraday trend and impact factor analysis on liquidity of Chinese futures market[J]. Systems Engineering-Theory \& Practice, 2013, 33(6): 1395-1401.

[38] Liu R Z and Zhou Y. "walking-the-dog" effect under order liquidity in futures and spots market- - based on high-frequency trading data with volume-clock[J]. Chinese Journal of Management Science, 2016, 24(4): 19-26.

[39] Yu S J, Wang C F, Fang Z M. Analysis of quasi-market makers' trading behavior characteristic in Chinese stock market[J]. Systems Engineering, 2016, 34(4): 1-8. 